\title{
"Thank you for playing science": Robotic Education at DLR_School_Lab RWTH Aachen
}

\section{Ms. Lana Plumanns M.Sc., RWTH Aachen University}

Since January 2015, Lana Plumanns has been a PhD student at the Faculty of Mechanical Enigeering at RWTH Aachen University, Germany. Within the Institute Cluster IMA/ ZLW \& IfU, she works in the research group Economic and Social Cybernetics. Before that she successfully finished her Master of Science Degree in Psychology. During her studies she has spent time abroad, studying at, among others, Concordia University, Canada. In her work as scientific researcher, she focuses on diagnostic factors in the field of (virtual) learning and cooperation, human-machine interaction, change and innovation management.

\section{Mr. Sebastian Reuter P.E., RWTH Aachen University}

Sebastian Reuter received a joint graduate degree (Dipl.-Wirt.-Ing.) in mechanical engineering and economics from RWTH Aachen University (Germany) in 2011. Between 2008-2009 he studied Automotive Engineering at Tsinghua University (China) where he received his M.Sc. in Automotive Engineering. He is currently working as a Ph.D. student at the Institute of Information Management in Mechanical Engineering at RWTH Aachen University. He is scholar of the German Research Foundation (DFG) in the Post-Graduate Research Program "RampUp Management". He holds a chair in the Organizing Committee of the RoboCup Logistics league and is a team leader of the Carologistics RoboCup team. His research interest are control and navigation of mobile robots with a special focus on inter-robot cooperation.

\section{Dr. Kristina Lena Lahl, RWTH Aachen University}

Dr. phil. Kristina Lahl has been the head of the "Economic and Social Cybernetics" research group at the Institute for Management Cybernetics (IfU) at RWTH Aachen University since Mach 2015. After having studied German and English Philology, as well as History, at the universities of Cologne, Prague and Cambridge, Kristina Lahl completed her doctorate $(\mathrm{PhD})$ as a scholarship holder at the a.r.t.e.s. Graduate School for the Humanities Cologne. Her PhD thesis focused on identity models in the transcultural space and used specific examples of German speaking literature from Bohemia and Moravia in the Czech Republic. Whilst a lecturer at the universities of Cologne and Olomouc and writing various publications, Kristina Lahl researched sociocultural references in German literature from the age of Enlightenment to the present using transdisciplinary approaches. Her main areas of research are sociotechnical narratives, ritualization and human self-assurance in interaction with artificial intelligence, as well as Second-Order Cybernetics.

\section{Dr. Rene Vossen, RWTH Aachen University}

Dr. Rene Vossen is Managing Director of the Institute for Management Cybernetics (IfU) at RWTH Aachen University. He completed his doctorate $(\mathrm{PhD})$ in the field of applied research on the intellectual capital of clusters of excellence. In addition his main areas of research are cybernetic knowledge management, the optimization of cooperation, communication and networking processes in knowledgeintensive research networks, quality management, performance measurement, metrics development and benchmarking as well as the research network management of inter-and transdisciplinary projects.

\section{Prof. Sabina Jeschke, RWTH Aachen University}

Sabina Jeschke became head of the IMA/ZLW \& IfU Institute Cluster of the RWTH Aachen University in June 2009. She studied Physics, Computer Science and Mathematics at the Berlin University of Technology. After research stays at the NASA Ames Research Center/ California and the Georgia Institute of Technology/Atlanta, she gained a doctorate on "Mathematics in Virtual Knowledge Environments" in 2004. Following a junior professorship (2005-2007) at the TU Berlin with the construction and direction of its media center, she was head of the Institute of Information Technology Services (IITS) for electrical engineering at the University of Stuttgart from May 2007 to May 2009, where she was also the director 
of the Central Information Technology Services (RUS) at the same time. Some of the main areas of her research are complex IT-systems (e.g. cloud computing, Internet of Things, green IT \& ET, semantic web services), robotics and automation (e.g. heterogeneous and cooperative robotics, cooperative agents, web services for robotics), traffic and mobility (autonomous and semi-autonomous traffic systems, international logistics, car2car \& car2X models) and virtual worlds for research alliances (e.g. virtual and remote laboratories, intelligent assistants, semantic coding of specialised information). Sabina Jeschke is vice dean of the Faculty of Mechanical Engineering of the RWTH Aachen University, chairwoman of the board of management of the VDI Aachen and member of the supervisory board of the Körber AG. She is a member and consultant of numerous committees and commissions, alumni of the German National Academic Foundation (Studienstiftung des Deutschen Volkes), IEEE Senior Member and Fellow of the RWTH Aachen University. In July 2014, the Gesellschaft für Informatik (GI) honoured her with their award Deutschlands digitale Köpfe (Germany's digital heads). In September 2015 she was awarded the Nikola-Tesla Chain by the International Society of Engineering Pedagogy (IGIP) for her outstanding achievements in the field of engineering pedagogy. 
"Thank you for playing science"- Robotic education at DLR_School_Lab RWTH Aachen

An Empirical Evaluation of the Status Quo and what follows

(Research Paper) 
The current developments being triggered by Industry 4.0 pose major challenges for robotic education; hence, the demand for students from fields affiliated with science, technology, engineering, mathematics and robotics in particular is steadily increasing. In this research paper, the "DLR_School_Lab_RWTH Aachen", an interdisciplinary student laboratory created to counter this challenge, is described and evaluated. Founded in 2013 by RWTH Aachen University and the German Aerospace Center (DLR), the DLR_School_Lab RWTH Aachen offers high-tech experiments in the field of robotics to secondary school students. Since its foundation, it has served as a highly successful extracurricular learning venue. Through active experimentation with robots in application scenarios and based on research from aeronautical, space, energy and transport fields, students have had the opportunity to receive an insight into different scientific disciplines and carry out hands-on experiments. The findings of this research suggest that the visit to the DLR_School_Lab RWTH Aachen enhanced the participants' interest in studying STEM fields. The results are under discussion and further steps, which take the results of these findings into account, are being planned.

1. Introduction

An increasing number of robotic systems are finding their way into our daily life and if trends continue, by 2020 robotics will rival the levels of the 2005 IT sector [1]. Due to the popularity and interest in service robots, robotics is no longer a field dominated by lavishly funded research laboratories; instead, it has become a multifaceted field that is seen as the future of services like radioactive waste disposal, military operations, mining, education and medicine [2]. Therefore, demand is increasing for competent robotic engineers that can contend within the transdisciplinary field of robotics, which requires lateral and innovative thinking, team-work and communication skills [3]. Classical engineering fields (mechanical, electrical and computer science) remain the gateways into robotics, though some special, holistic university programmes are being developed [4]. Authentic, scientific and technological research environments are popular amongst secondary school students, in response to which successful student laboratories, which provide various stimuli, enhancement potentials and supplements in secondary school education, have been established for STEM field subjects [5, 6, 7]. In turn, robotic assistance has been shown to have significant positive effects on the education of children in computer education, sciences and second language learning [8].

In reaction to these trends, RWTH Aachen University has established the DLR_School_Lab, where pupils get a feel for what it takes to be a robotics engineer and gives them hands-on experience into the field of robotics itself. This paper aims to outline what the DLR_School_Labs are, what the DLR_School_Lab_RTWTH Aachen offers, how it is reacting to contemporary trends, and lastly provide an evaluation of the impact the Lab has on student affiliation with STEM fields. 


\section{The DLR_School_Labs}

The German Aerospace Center (DLR), one of Europe's largest research institutions, is developing the aircraft technology of the future, training pilots, testing rocket engines and analysing images of distant planets. It also helps run the 12 DLR_School_Labs currently in operation throughout Germany. Authentic learning environments, self-guided high-tech experiments and competent scientific advice are the three pillars that define the DLR_School_Labs [9], with self-guided experiments being the core concept. Moreover, each of the School_Labs has its own focus area. The DLR_School_Lab_Berlin, for example, primarily investigates our solar system, whereas the DLR_School_Lab RWTH Aachen focuses on robotics and artificial intelligence, largely due to the strong interest in mechanical engineering at the RWTH University.

The experiments conducted here at the DLR_School_Lab RWTH Aachen cover questions from the fields of aeronautics, space, energy and transport research. Experiments involve the development of artificial intelligence in the regulation of renewable energy supply for the "city of the future", analysis of quadcopters' flight characteristics, drive simulations testing the lateral dynamics of an automobile, and a humanoid robot walking and dancing. Furthermore, RWTH Aachen's "Holodeck" enables a virtual walk on Mars and the investigation of robotic exploration vehicles on the planet.

In alignment with the ideas of the DLR_School_Labs, Mubin et al. argue that learning about the real world is facilitated by learning through experiences in a virtual world and via practical experience. Moreover, they argue introducing robots into education in a more informal setting encourages knowledge retention, especially if there is a social or practical element to the teaching procedure [8]. In line with the above argument, the DLR_School_Labs, under the guidance of real scientists and students of the RWTH Aachen University, use authentic, high-tech equipment to inspire and challenge participants, which results in high attention rates of the students.

The experiments last an hour each and are carried out according to the participants own personal interest and are guided by leading questions from the scientist or university student of that field. During which time the necessary knowledge is attained in a self-dependent way, and a sense of personal responsibility for the state-of-the-art, high-tech equipment (e.g. humanoid robots, quadcopters, etc.) is encouraged and developed.

\subsection{The DLR_School_Lab RWTH Aachen}

The DLR_School_Lab RWTH Aachen was founded in 2013. Since its foundation, more than 2000 secondary school students have visited the DLR_School_Lab RWTH Aachen and conducted hands-on experiments. The DLR_School_Lab_RWTH Aachen takes place in a room with a floor space of $330 \mathrm{qm}$; consisting of two large halls filled with interactive robot exhibits used in the experiments (including the industrial robots ABB IRB 120, Kuka Youbot; two humanoid NAO robots; the Holodeck; various kinds of Drones (AR Drones and AscTec Hummingbirds); as well as different kinds of Lego Mindstorms (from Wowee till Ev3)) and a separate teaching room. Since its foundation, and even after the scientific designs of the experiments were decided upon, the courses and experiments have been continuously developed, taking into consideration the newest technology, didactic education and student feedback.

Eight student assistants and two scientific researchers work at the school lab, continuously improving and conducting the experiments offered to the visiting schools, universities, charitable and private organisations up to seven days per week. Moreover, it is the task of the 
scientific researcher to get in touch with the different organisations, make appointments, serve as contact to the aforementioned organisation, provide assistance to the students and supervise the development of the experiments. The student researcher prepares the robots and experiments, conducts them and supervises the participants during the practical phases of the experiments, all of which is conducted in the halls as well as at schools, scientific exhibitions and organisations. Furthermore, the DLR_School_Lab_RWTH Aachen also organises events, like girls' days, days for refugees and days that involve schools from all over the world, all of which encourage interest in the sciences and technology.

Frequent exchanges of information with the other school labs, the institute, the university's state of the art science equipment and its fast adaption to contemporary conditions enables a sustainable teaching and learning environment to be developed.

Martin Wagenscheid's didactic concept, 'Inquiry-Based Science Education' (IBSE), which uses cross-linked teaching and research approaches, forms the basis of all teaching methods of the twelve DLR_School_Labs [10,11]. A recent European Commission study has recommended the methodology due to the positive effects it has had on students' educational attainment and achievements [12]. This IBSE-cycle, central to the DLR_School_Lab RWTH Aachen, is further developed in the IMA/ZLW \& IfU institute cluster's training model [13].

\section{Related projects in the field of extracurricular learning venues}

There is increasing interest in extracurricular learning venues where students and scientists can promote and deepen interests in their specific field. In the United States and Japan, for example, there are some excellent universities concerned with robotic science e.g. the University of California at Berkeley, the Robotic Society of Japan, and the University of York. However, in contrast to these laboratories, which are exclusively available for senior researchers or at least PhD students, the DLR School Labs focus on a much younger target audience. The project aims to awaken interests in engineering sciences, whilst testing the potential a pupil has. This is of relevance because the DLR_School_Lab_RWTH Aachen exhibits topics pupils can study at RWTH Aachen University, an excellent university right on their doorstep.

Around the globe, there are other laboratories that work in equal or related fields within robotics, though very few are constantly available for students and carry out hands-on experiments. This is largely due to the equipment often being very expensive and too complex for young people to use. The specific challenge of creating a lab for pupils is to give them something that inspires them, makes them curious, makes it look achievable, and similar to the reality of working in the respective engineering field. It was for this reason that the DLR School_Lab_RWTH Aachen was begun three years ago.

Due to concerns about the increasing demand for future engineers and the significance of qualitative scientific and technological education, universities and other seats of learning are focusing on secondary school students. Hence, since 1990 School labs have been an important component of education in German universities [23].

4. Visiting the lab \& the didactic concept behind it

A typical visit at DLR_School_Lab RWTH Aachen lasts six hours, with the student group entering the multifunctional teaching room on arrival, which is filled with multimediasupported presentations of interactive robot exhibits (e.g. autonomous ground vehicles, rescue robots, humanoid and insectoid robots, etc.). This relaxed introduction to robotics reduces any reservations that the students might have about the field of robotics. After a welcome phase, a 
short lecture is given introducing some of the main themes of robotics and the core research areas studied by the scientists and robotic engineers at DLR and RWTH Aachen University.

A small group size of four to six persons allows for active participation in the six practical experiments, of which each group carries out four, and the necessary concentration for handling the high-tech equipment. Each experiment is followed by a short break, allowing the students reflection time to discuss the experiments with their peers. Each experiment starts with a clarification of the educational targets and an outline of the skills that will be attained by the end of the experiments [14]. Clarifications provided by the supervisor facilitate the learning process as the students receive a forecast of the expected results and gain motivation from their own empirical findings [15]. The educational targets of the experiments are not explicitly stated in a list, but are instead introduced by the scientist or university student supervising the experiment. At the beginning of each experiment, the equipment is explained and the problem to solve is stated. The students and supervisor analyse the problem and identify the necessary steps to be taken and in doing so, the desired outcomes of the experiment are met.

The students' prior knowledge of and experiences with similar problems and technologies are then discussed - covering personal skills, experiences and emotions linked to the content of the experiment, a matter essential to the learning process according to Ausubel [16]. Alongside prior knowledge, emotions also greatly influence learning [17]. The integration of individual experiences and emotions with the experiment content activates the student's background knowledge and allows for subsequent information to be assimilated. The focus on the experiment's relevance to the everyday motivates learning, as the knowledge encountered is seen to be of importance, rather than just something to memorise and easily forget [18].

The combination of both theoretical and practical factors has been proven to facilitate the best learning environment and stimulus [19]. The theoretical foundations of the experiments are presented in short teaching sessions, during which time information about solving typical problems in the specific field of interest are divulged. An individual research phase follows, involving further analysis of the aforementioned problems and possible solutions that could be achieved through experimentation. During these practical sessions, the supervisor simply handles the equipment, instead of attempting to influence problem resolution. Open-ended problems enable 'Inquiry-Based learning', thus encouraging the students themselves to question, obtain and explain evidence whilst deriving strategies for problem resolution.

Silva et al., argue that students perceive and process experiences in different ways [20], meaning that the experiment supervisor must adapt the experiment's practical and theoretical content to fit the target group. If he/she chooses to start with the theoretical input, the practical input follows and then so does the reflection phase, and vice versa. This stage is concluded by a period of reflection, where the solutions developed are presented and discussed amongst the students, enabling previous insights to be developed, perspectives widened and possible future improvements discussed [19].

The following section outlines six of the experiments: Autonomous Flight Systems, A Walk on Mars, Renewable Energy, Autonomous Vehicles, Industrial Robots, Humanoid Robots, all of which maintain the core didactic concepts central to the aims of the DLR_School_Lab RWTH Aachen. 


\subsection{Autonomous Flight Systems - how technology gets airborne}

The experiment "Autonomous Flight Systems" covers two different topics: the physics and control principles of multicopters (helicopters with more than one rotor) and the handling of the control devices. A detailed description of the physics and aerodynamic principles at play must be held before the experiment begins. Students learn how the dynamic lift on air foils enables aircrafts to fly and in a short, individual experiment, the students sit on a swivel chair and try to rotate it solely by moving their arms, thus experiencing the torque effect. In a follow-up discussion, the students analyse the respective directions of rotation of the individual propellers of a quadcopter (Fig. 1) and learn about torque compensation. The students thus experience the effect speed changes have on individual rotors of a suspended quadcopter. They also learn to tilt the quadcopter around its axes, clearly embodying the physical principles that enable a quadcopter to fly and steer whilst hovering in the air.

After this brief explanation and analysis of the physics principles, the students get the chance to fly the quadcopter on their own, making use of various control devices including keyboards, game controllers, a tablet PC and gestures in front of a Kinect camera. The task is to manoeuvre the quadcopter around obstacles using at least two different control devices, which is then followed by a discussion on the control principles of the quadcopter. The students reflect on the suitability of the different control devices by applying different design criteria for user interfaces and the students derive their own definitions of robotic intuition, taking into account control devices and the guidance given by the supervisor.

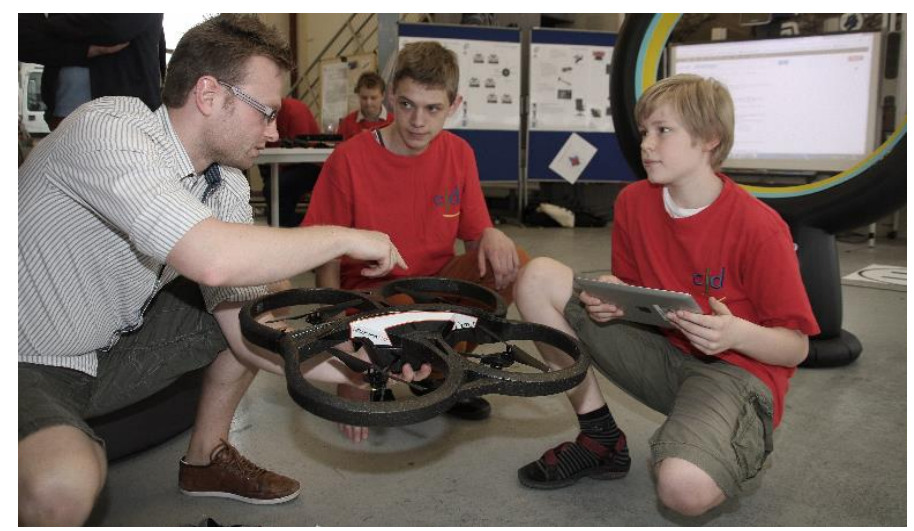

Fig. 1 - Experiment Supervisor explaining the control principles of a quadcopter

\subsection{A Walk on Mars - experiencing remote worlds locally}

"A walk on Mars" analyses the challenges associated with the robotic exploration of Mars and the potential outcomes it may bring. Leading questions revolve around why Mars is significant in space exploration and how helpful autonomous robots are to this research. Students use the IMA/ZLW \& IfU's Holodeck (Fig. 2) after a short introduction that outlines some select Mars missions, their challenges and results. The Holodeck is a simulator comprising of an Oculus Rift head mounted display, IR tracking and an omnidirectional treadmill, thus allowing the participant's position to be determined in the real and virtual environment, whilst also allowing and infinite expansion of the walking environment (Fig. 2).

Discussions will centre around the comparisons between the key features of Mars and Earth such as planet size, water resources and the atmosphere composition, surface features (volcanoes, impact craters, polar areas etc.). The term "follow the water" is central to the leading questions of the experiment: Can life be found on Mars and could it exist there today? and consequently: What would this mean for a manned mission to Mars? 
The main discussions will occur while the students are engaged with the holodeck. Within the virtual environment, students find models of autonomous vehicles that have been sent to Mars to search for water and signs of life. When a new probe is discovered, the student on the Holodeck describes it to the group and discussions are held about the possible functions of the components of the probe. A gallery of the most important facts is shown at the end in order to summarise the experiment and highlight key pieces of information.

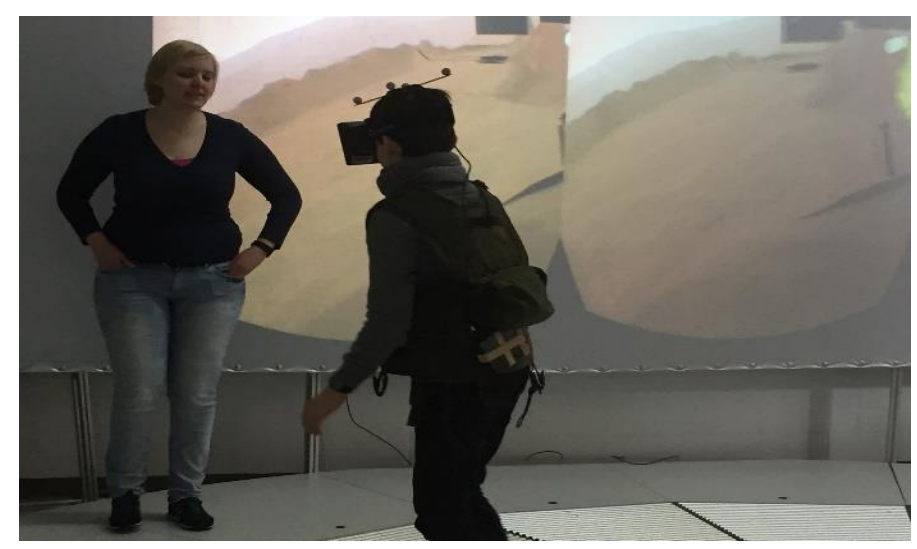

Fig. 2 - Student exploring the Mars Rover, an opportunity available in a virtual "Walk on Mars"

\subsection{Renewable Energy - where will tomorrow's energy come from?}

Methods surrounding the future of energy supply are discussed in the experiment "Renewable Energy". The SmartCity demonstrator (Fig. 3) enables students to investigate strategies for predicting and stabilising energy requirements of an "intelligent city" in an environmental and sustainable manner.

Using the SmartCity demonstrator, the students supply a small town with sufficient energy, using a mixture of renewable energy resources like solar panels, wind turbines and a pumpedstorage hydroelectric plant, with a marble run depicting the energy units. Most components of the demonstrator are made of LEGO to allow for easy handling.

Of the five groups, two groups control the angles of the solar panels and wind turbines, one simulates the sun with a hand lamp, one controls the wind with a fan and finally one coordinates the others and controls the hydroelectric power station. Their task is to supply the city with sufficient energy on a fictive day, taking into account the intensity and angle of the sun and wind and the demand for energy from the city. Therefore, excess energy must be stored in the hydroelectric power station during phases of surplus energy (high intensity sun and wind), which is then utilised during phases of peak demand and times of low intensity sun and wind. The supply levels are depicted in a graphical interface in real-time.

Students then reflect on the difficulties associated with power distribution, the strategies used to deal with it and they later learn the science behind the renewable energy sources they used in the experiment. The students discuss prediction methods for energy requirements and devise sustainable, environmentally friendly methods for meeting requirements. Strategies and control logic is mapped out on a whiteboard and UML so that energy supply solutions of a smart city can be developed [20]. The supervisor makes logic components available and assists the students in their implementation in Labview [21]. The students then watch the SmartCity demonstrator distribute the energy based on the logic inputted by the students, which is then followed by a discussion about future energy supply, with a focus on the decentralisation of energy supply on a Smart Grid. 


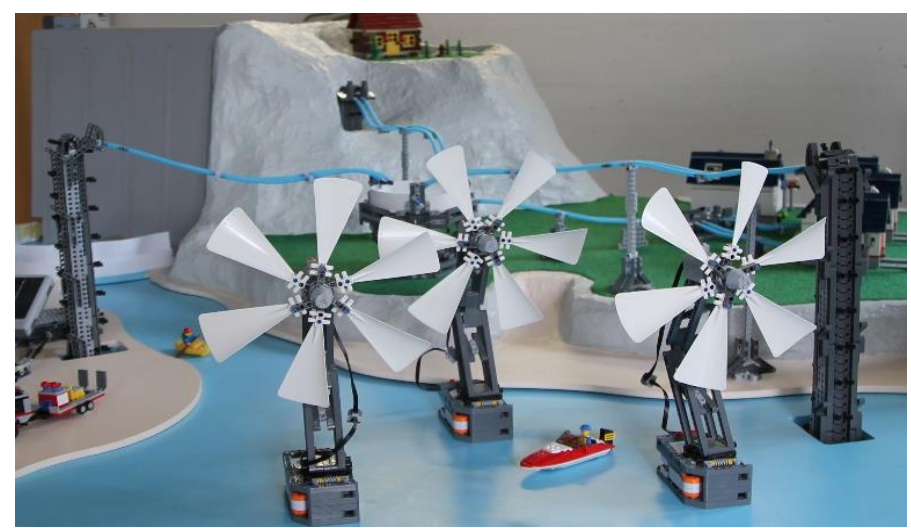

Fig. 3 - A marble run clarifying relationships in smart grids

\subsection{Autonomous Vehicles - real phenomena in virtual worlds}

A driving simulator is used in the experiment "Autonomous Vehicles" to explain mechanical and autonomous systems within the field of transportation. The goal is to show the dynamic stability of a car through control loops. The students learn the importance of control theory in autonomous systems that are part of their daily lives (e.g. temperature regulations in refrigerators). Through the use of numerous examples, students become familiar with control loop elements, as human and technical analogies have proven to be useful learning stimulus for students (Fig. 4). An example is the analysis of a human performing a simple control task (like filling a cup with water), which is then broken down and the corresponding control loop elements are identified - the human brain as the control unit, human senses are sensors and muscles actuators.

PID control (proportional-integral-derivative control) is also introduced in more detail. The age of the students and their knowledge of mathematics also determines whether the calculations behind the control loop should be introduced, or whether simply its behaviour is discussed. This new knowledge is put into practice in the following experiment that sees students attempting to manually follow a line on the road by turning the steering wheel, ultimately showing the challenges of following the line at high speeds. This is followed by a control loop guiding the lateral control of the virtual vehicle, whose PID is initially set to zero. The students experiment with the coefficients, the influence of the rate of proportionality and the differential or the integral gain. In doing so the students experience the oscillating, amplifying or compensating behaviour of the virtual car while following the line, whilst also analysing complex mathematical correlations and visual feedback from the driving simulator in a trial-and-error method. This method interweaves theory with practical experience and leads to an internalisation of learned knowledge, which is only improved upon by the fun and interesting knowledge acquisition method.

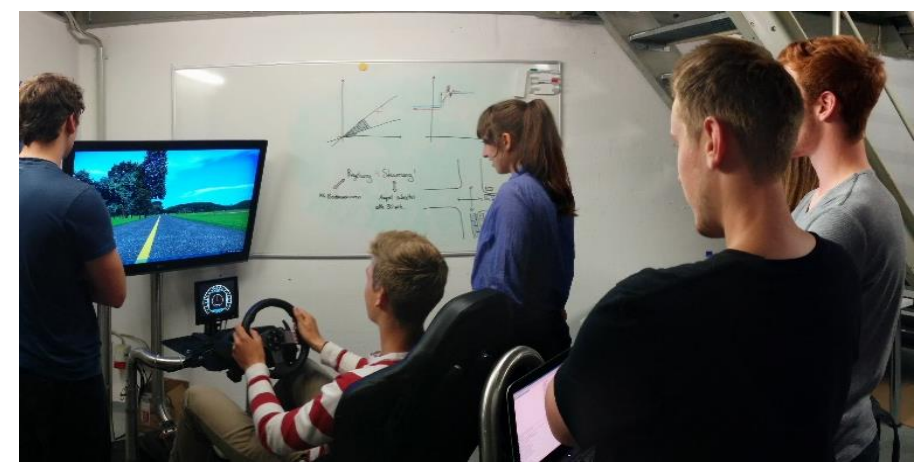

Fig. 4 - Students tuning control algorithms in a driving simulator 


\subsection{Industrial Robots - musclemen who lend a hand}

This experiment is involved with the study of industrial robots and explores the constraints of a 6-axes industrial robot, with a focus on its geometry and control capabilities. The robot used in the experiment is shaped similarly to a human arm, though complex calculations are needed for even simple movements (Fig. 5). In the theoretical phase of the experiment, the history of industrial robots and different types of robot arms are introduced, this is accompanied by an interactive presentation depicting industrial robots and guesses are made about their function, field of application and work space (geometric range in which the robot can fulfil its task). The students then use a LEGO Mindstorm model of a three-joint industrial robot and are equipped with protractors for measuring the angles of the different axes. The student's task is to measure the coordinates of the tool centre point (TCP- the "finger-tip" of the arm), using specific angles to move the robotic arm joints, thus introducing the theoretical concepts of forward and backwards kinematics and the use of Pythagoras for calculating the position of the TCP.

Students, having been given a target position for the TCP, must find the suitable angles of the different robotic-joints in order to reach the desired target position. During the discussions, students experience the problems associated with multiple angle configuration of inverse kinematics, which leads to the conclusion that there is no single, undisputable path for robots to follow during movement, and also that there may even be points that cannot be reached due to the design of the robot. A theoretical phase follows, which graphically introduces and explains the concept of inverse kinematics. Finally, the students experience the concepts of forward and backward kinematics using a real ABB IRB120 industrial robot, which the students programme to follow a "Hot Wire" without touching it.

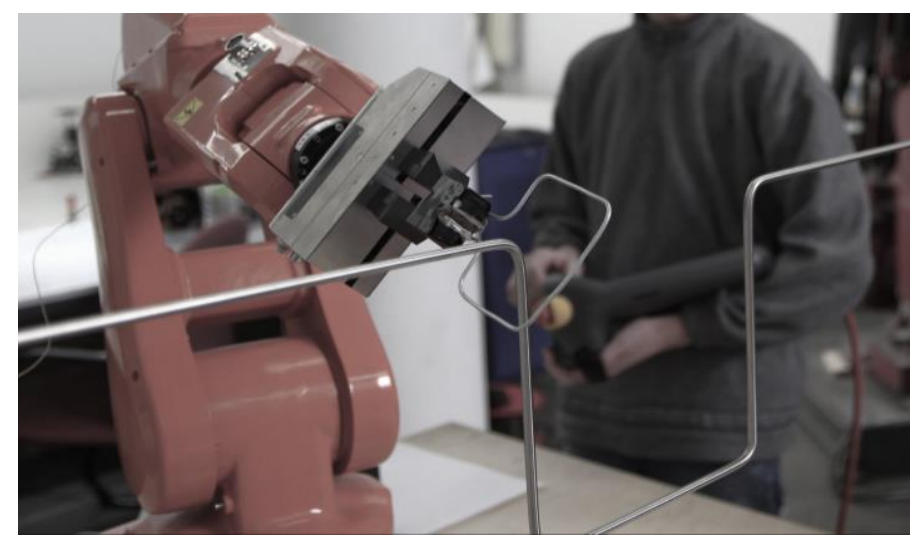

Fig. 5 - Student controlling an industrial robot to follow the "Hot Wire"

4.6. Humanoid Robots - using humans as the model

This experiment discusses the dynamics of the human gait using humanoid robots. The aim of the experiment is to familiarise the students with the complexity of human movement and to give them the skills necessary to control a humanoid robot. Consequently, students learn calculations for stabilising the equilibrium of a multi-body system.

In the theoretical stage of the experiment, the students are informed about the motives for studying humanoid robots and their characteristics, with emphasis also being placed on what it is that defines a human. The students are encouraged to question their personal concepts and think about the difficulties they had as toddlers when learning specific human abilities (grasping, crawling and walking upright, etc.), leading to the conclusion that robots also face the same problems. The experiment involves discussions about evolution, the development of 
the bipedal human gait and observations about walking upright. The students analyse the process of taking a step using a tennis-ball attached to their waist by a thread, which depicts the line of action in relation to the human centre of gravity, as well as in relation to hip and foot movements. These observations are then easily applied to the humanoid system being used in the experiment.

The humanoid system used is a NAO robot (Fig. 6), which has a similar joint-configuration to the human physiognomy. The students work on a set of balancing tasks in groups of two or three and test their findings on their own body. They discuss their solutions with the other groups to find a consensus and try out their ideas on the NAO robot.

Depending on age and physics knowledge, the course can be expanded to include calculations regarding the centre of mass, which in turn can be used to verify the results the students found at the earlier stage. Over the course of several experiments, it was found that the performance and speed of the students did not depend on their age or school system - even adults needed similar amounts of time to solve the problems. An analysis of the experiments is outlined in the following section.

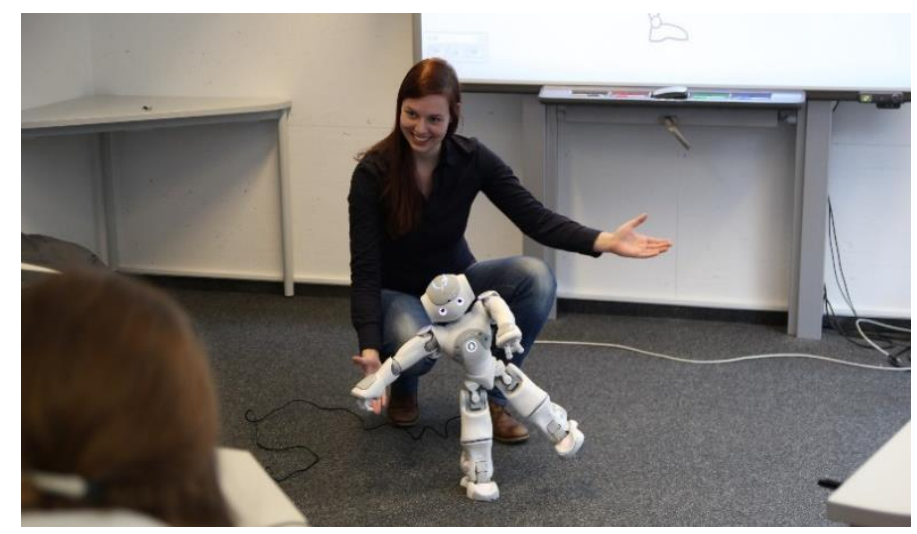

Fig. 6 - Experiment Supervisor explaining the balance principles of a NAO robot

\section{Analysis}

The evaluation of the DLR_School_Lab started in 2014. Since then 649 secondary school students (297 female/352 male) aged between 12 and 18 years $(M=15.3 ; S D=1.6)$ have participated. The questionnaire was developed in cooperation with the DLR and the RWTH Aachen University and was comprised of demographic data, questions about the duration of visit, the introduction, supervision and the complexity and content of experiments, questions about how the visit influences the participant's behaviour and their subsequent affiliation to STEM-fields. The questionnaire is comprised of questions based on a 5-point Likert scale, dichotomic (yes, no, maybe) and open-ended questions. Participants' views were assessed anonymously after the visit so as not to distort the results. The experiments participants participated in (ranging from 3-5, mostly 4 of the experiments) depended on their background education and interest. Kind and number of experiments, as well as complexity of tasks and duration of visit, were arranged before the visit of the lab.

The resulting data was analysed using IBM SPSS. Due to significance of the Shapiro-Wilk test of normal distribution, some of the variables were not normally distributed. Therefore, the non-parametric Kruscal-Wallis test was used to examine discrepancies in the experiment evaluation of age groups (younger pupils (grade 6-9) vs. older pupils (grade 10+)) and gender. However, the analysis of the data showed that there were no significant differences between the gender nor the age groups when it came to evaluation of the six experiments. The 
introduction to the experiments was rated as fairly good $(\mathrm{M}=1,37 ; \mathrm{SD}=.55 ; \mathrm{N}=649)$ as was the supervision $(\mathrm{M}=1,21 ; \mathrm{SD}=.35 ; \mathrm{N}=649)$. The content of the six experiments was rated as follows: $\mathrm{M}=1.42, \mathrm{SD}=.63, \mathrm{~N}=649$ (humanoid robots), $\mathrm{M}=1.42, \mathrm{SD}=.58, \mathrm{~N}=621$ (walk on Mars), $\mathrm{M}=1.43, \mathrm{SD}=.65, \mathrm{~N}=534$ (autonomous vehicles), $\mathrm{M}=1.45, \mathrm{SD}=.62, \mathrm{~N}=456$ (autonomous flight systems) and $\mathrm{M}=1.45, \mathrm{SD}=.43, \mathrm{~N}=113$ (renewable energy) and $\mathrm{M}=1.46$, $\mathrm{SD}=.60, \mathrm{~N}=247$ (industrial robots). All of the questions described above were thereby rated on a 5-point Likert scale, ranging from 1=fully applicable to 5=fully inapplicable. In the dichotomic set of questions, were the answer was yes, no or maybe, most of the participants checked that they would like to visit the lab again (91.7 percent) and almost all participants stated that the visit increased their interest in STEM fields (92.1 percent). This effect was more noticeable in the female sample, though not by a significant amount. During the experiments it was possible, through observation, to note that women were slightly more active during the humanoid robot experiments, whereas men tended to be more active when it came to the experiments with drones. However, these slight discrepancies show no significant differences when it came to the evaluation of the experiments.

In the dichotomic questions, most of the participants answered that as a result of the visit, they were now able to recognise the importance and meaning of STEM and robotic topics in the everyday and more specifically in their future lives (93.1 percent). Furthermore, data indicated that the visit to the DLR_School_Labs RWTH Aachen enhanced the participants' interest in studying fields affiliated with science, technology, engineering and mathematics. This attraction was also pronounced in the female sample. Over 79 percent of the participants intended on starting their future career in this sector as a result of the rewarding experiences they had had in the Lab.

\section{Discussion}

The main aim of the study was to evaluate the status of the courses offered to students using experiments. Our results clearly indicate the positive effects that the various experiments had on participants during their visit, which in turn is seen to affect the participants' desire to study STEM fields in the future. The visits have had positive impacts on students and have affected their future career plans.

Over the past couple of years, a great deal of effort has been put into the promotion of STEM fields in education, resulting in the creation of numerous school laboratories aiming to interest students in science through practical experience [22]. Questions arise regarding the real impact and long-term effects these laboratories have. However, Pawek [23] conducted a study showing that there is a positive long-term impact on students within the scientific fields if they have undergone experiences like those offered by the DLR_School_Labs. The findings show that even after one year, the majority of students would agree that the experiments 'are fun' and important for their academic and vocational education, with half the participating students stating that they want to continue working within the topic areas covered. Possible explanations for these opinions include the stimulating learning environment that is created through practical experiments with high-tech equipment and an authentic research laboratory $[22,23]$. In this study, interest in high-tech machinery was noted at DLR_School_Lab RWTH Aachen, perhaps due to the fact that schools often cannot offer that kind of robotic equipment and expertise. Therefore, there is clear proof that a visit to the DLR_School_Lab RWTH Aachen stimulates an increased interest in science and a sustainable interest in robotics.

The questionnaire was designed to give an overview of the status quo surrounding the success of the DLR_School-Labs and highlight the strengths and weaknesses of experiments actually used for technological development. Given the current results, no specific areas for 
improvement in optimisation can be identified. Future questionnaires may be based on a larger scale (eg.- a 7 or 9-point scale) to assess more minute differences between participants. During the analysis, additional factors that deserve attention in future evaluations gain prominence - pre-knowledge and previous interest in this field of robotics for example. An extension of the questionnaire might also be an option in order to evaluate the trends shown in this experiment (a link between theoretical amount and evaluation of female and respectively male participants, or conversely costs and evaluation). A longitudinal evaluation study over a longer time period would also be interesting in order to gain a deeper insight into the further development of student education. Furthermore, the integration of more open-ended and detailed questions within the questionnaire, or even carrying out a follow-up interview with willing participants could be promising within future research, due to the valuable suggestions they could provide.

\section{Conclusion: Summary \& Outlook}

As a multidisciplinary field, robotics represents a wide range of scientific fields, though it is facing a shortage of skilled workers. The DLR_School_Lab RWTH Aachen aims to attract students to STEM fields, and to robotics in particular, through the use of research laboratories and high-tech equipment, which students have a personal responsibility to look after. An enquiry based, didactic learning cycle is applied in order to encourage independent problem solving, of which there are five steps- clarification of educational targets, eliciting of prior knowledge and experiences, flexible arrangement of alternating theoretical and practical inputs, and the reflection on the learning process. This approach is continued throughout the rest of the institute cluster IMA/ZLW \& IfU and it is this approach that makes the DLR_School_Lab RWTH Aachen a unique experience.

The results show that it is not just the lab that is popular. For many adolescents it also creates a situational interest and improves and broadens their set of abilities, which in turn affects their future career plans. Further steps in the realm of adult and teacher education have also been planned due to the increasing demand for advanced training courses in industrial and humanoid robotic fields and virtual learning methods, which includes the use of the Oculus Rift headset.

Due to the increasing number of international inquiries from schools across the world, we also plan on offering our experiments in languages other than just German and English - French and Dutch are among the languages being considered at the moment. Additionally, a further integration of more remote labs might also be promising in achieving the full utilisation of the institute's existing infrastructure and resources.

The results of the experiment evaluations were excellent; therefore, there is no urgent need to modify the existing experiments. The implementation of follow-up interviews and the extension of the questionnaire, alongside the results of the existing questionnaire, would enable scientists to garner more knowledge about areas where improvements are needed in the future.

\section{Acknowledgements}

This work was supported by Deutsches Zentrum für Luft und Raumfahrt (DLR) and the authors would like to thank Dr. Kratzenberg-Annies from the DLR for his help in establishing the DLR_School_Lab RWTH Aachen, as well as all other DLR_School_Labs for their cooperation. 


\section{References}

[1] The University of Auckland Robotics Research Group, Robotics History Timeline (2006). Online: http://robotics.ece.auckland.ac.nz/index.php?option=com_content\&task=view\&id=31\&Itemid= [Jan 2015]

[2] Singh, B., Sellappan, N., \& Kumaradhas, P. (2013). Evolution of Industrial Robots and their Applications. International Journal of Emerging Technology and Advanced Engineering, 3 (5), 763-768.

[3] Khanlari, A. (2013). Effects of Robotics on 21st Century Skills. European Scientific Journal, 9 (27), 2636.

[4] Moulton, B., \& Johnson, D. (2010). Robotics education: a review of graduate profiles and research pathways. World Transactions on Engineering and Technology Education,8 (1), 26-31.

[5] Kircher, E., Girwidz, R., \& Häußler, P. (2010). Schülerlabore: Lernen durch forschen und entwickeln. In Kircher, E., Girwidz, R., \& Häußler, P. (ed.) Physikdidaktik, Springer Berlin Heidelberg, 799-818.

[6] Hansen A., Hees F., Jeschke S.: Hands on Robotics. Concept of a Student Laboratory on the Basis of an Experience-Oriented Learning Model. Proceedings of the International Conference on Education and New Learning Technologies, In: EDULEARN 2010, 5-7 July 2010, IATED, pp. 6047-6057, Barcelona, Spain.

[7] Stehling, V., Schuster, K., Richert, A. \& Jeschke, S. Access All Areas: Designing a hands-on robotics course for visually impaired high school students, in Proceedings of the International Conference on Human Computer Interaction (HCI 2015); 1-8 August, Los Angeles, USA.

[8] Mubin, O., Stevens, C.J., Shahid, S., Mahmud, A.A., and Jian-Jie, D. A Review of the Applicability of Robots in Education (2013). Online: http://roila.org/wp-content/uploads/2013/07/209-0015.pdf [Jan 2015]

[9] Schüttler, T., \& Hausmann, D. (2011). Das DLR_School_Lab Oberpfaffenhofen. Ein besonderer außerschulischer Lernort. Schulverwaltung. Bayern, 34 (2011), 12, 324-327.

[10] Wagenschein, M. (1962). Die pädagogische Dimension der Physik. Grundthemen der pädagogischen Praxis. G. Westermann, Braunschweig.

[11] Wagenschein, M. (1980). Naturphänomene sehen und verstehen. Genetische Lehrgänge. Hrsg. v. H.C. Berg. E. Klett, Stuttgart.

[12] European Commission (2007). Science Education NOW: A Renewed Pedagogy for the Future of Europe. Luxembourg: Office for Official Publications of the European Communities.

[13] Bücker, M., Müller, L., Borowski, E., Vossen, R., \& Jeschke, S. (2014). A Training Model for University Teaching Staff. In: Automation, Communication and Cybernetics in Science and Engineering 2013/2014. Springer-Book. Springer Berlin Heidelberg. 2014. pp 223-229

[14] Moss, Connie M., \& Susan M. Brookhart. (2012). Learning targets: Helping students aim for understanding in Today's lesson. Alexandria: Asociation for Supervision \& Curriculum.

[15] Smith, M. K., \& Perkins, K, (2010). At the end of my course, students should be able to...: The benefits of creating and using effective learning goals. Microbiology Australia, 31, 32-34.

[16] Ausubel, D. P. (1968). Educational psychology: A cognitive view. NewYork: Holt, Rinehart and Winston.

[17] Silva, D.,Sabino, L., Adina, E., Lanuza, D. \& Baluyot, O. (2011). Transforming Diverse Learners through a Brain-based 4MAT Cycle of Learning. Proceedings of the World Congress on Engineering and Computer Science 2011, Vol 1, WCECS 2011, October 19-21, 2011, San Francisco, USA.

[18] Cipi, E. (2014). How to Integrate ICT with Didactic Learning Approaches. Journal of Educational and Social Research, 4(1), 325-331. 
[19] Michael, J. (2006): Where's the evidence that active learning works? Advances in Physiology Education, 30, 159-167.

[20] Object Management Group, Unified Modeling Language (UML). Online: http://www.uml.org/ [Jan 2015]

[21] National Instruments. LabVIEW System Design Software, http://www.ni.com/labview/d/ [Jan 2015]

[22] Priemer, B., \& Pawek, C. (2014). Out-of-school STEM learning in Germany: Can we catch and hold students' interest?

[23] Pawek, C. (2009). Schülerlabore als interessefördernde außerschulische Lernumgebungen für Schülerinnen und Schüler aus der Mittel- und Oberstufe.

Online: http://www.dlr.de/schoollab/Portaldata/24/Resources/dokumente/Diss_Pawek.pdf 